\title{
Três hipóteses sobre as relações entre mídia, entretenimento e política
}

As relações entre mídia e política ocupam um largo espaço na agenda de pesquisas sobre comunicação. Ao longo do século XX, estudos tanto no campo político quanto na área de mídia sublinharam vários aspectos dessa relação. Parece haver tantas hipóteses a respeito das ligações entre mídia e política quantas possibilidades de análise, e alguns dos trabalhos clássicos na Comunicação emergiram justamente dessa interseção.

Estudos a respeito da influência da mídia no público, abordando direta ou tangencialmente a questão política, foram usados pelos clássicos da comunicação tanto para sublinhar o poder de persuasão da mídia (Lasswell, 1957) quanto para negá-lo (Katz, 1957); hipóteses a respeito da definição de uma agenda política (McCombs e Shaw, 1972) ou da resistência do público (Louw, 2005).

Nas últimas décadas, entretanto, outra ramificação desses estudos parece ter se desenhado no horizonte da pesquisa. Trata-se de um deslocamento de foco: ao estudo das campanhas eleitorais e das pesquisas de opinião, nas quais se observam os tangenciamentos do processo político com o jornalismo e/ ou a propaganda e o marketing, é acrescentada uma vertente de estudos direcionados para conhecer as relações entre entretenimento e política (Brants e Neijens, 1998, p. 150; Panke, 2010).

Tradicionalmente, há uma visão negativa nessa relação: o entretenimento, sob os nomes "cultura de massas", "indústria cultural" ou "cultura popular", levaria à progressiva alienação da sociedade a respeito da política. Um 
ponto de partida dessa tradição crítica, estimulada pelo uso do entretenimento como propaganda política recentes de, por exemplo, Postman (1986) e Putnam (1995).

Se os argumentos desses autores, em linhas gerais, reconhecem a presença cotidiana da mídia e a impossibilidade de separá-la do processo político, há uma premissa negativa: o entretenimento desvia a atenção das coisas importantes (Postman, 1986) e desmantela o engajamento cívico, criando problemas para a democracia (Putnam, 1995).

Em anos recentes, alguns pesquisadores estão procurando rever essa tradição de estudos, sem deixar de lado uma visão crítica, mas avaliando a pertinência de alguns de seus pressupostos em uma sociedade dominada pelos meios de comunicação (Street, 2005, p. 17). Neste texto, o objetivo é apresentar três dessas hipóteses a respeito das relações entre entretenimento e política. A escolha foi feita por conta de uma unidade subjacente às três: a ausência de uma condenação a priori da mídia, de um lado, articulada com um exame crítico das relações entre comunicação e política na esfera do entretenimento, de outro.

No que segue, serão apresentadas e brevemente discutidas três hipóteses que explicam essa relação. Dentro dos objetivos do texto, a ideia é antes apresentar do que discuti-las em sua extensão, assim como não se entrará na problemática a respeito do que constitui, epistemologicamente, uma "hipótese" - o termo é usado por conta da fluidez do texto e do caráter experimental das proposições. Assim, em primeiro lugar, a concepção de Thomas Meyer (2002), a mídia "colonizou" a política; em seguida, para John Street $(2001 ; 2005)$, a percepção de que o entretenimento é uma forma de política; finalmente, a perspectiva de "convergência" entre formatos da mídia e da política postulado por Liesbet Van Zoonen (2004; 2005). A tradução dos trechos em inglês, salvo menção em contrário, é do autor.

\section{A mídia colonizou a política}

Um dos argumentos para explicar as relações entre mídia, entretenimento e política foi formulado pelo cientista político alemão Thomas Meyer em Media democracy (2002). Seu pressuposto, em linhas gerais, é que a mídia teria colonizado a política, fazendo com que elementos desta última passassem a seguir as demandas e particularidades da primeira. Em suas palavras, a "lógica da política" passou a seguir a "lógica da política". Isso representa, 
em princípio, entender que certas transformações da política acontecem no sentido de seguir um certo padrão em suas relações com a mídia.

A pesquisa sobre mídia e política, acredita Meyer, tem focado primariamente no modo como a política é retratada nos jornais e televisão e na transformação, pelo marketing, dos elementos políticos em produtos. Pouca atenção tem sido dada, acredita, às transformações que o uso da mídia provoca na política em si.

Em termos gerais, Meyer define a perspectiva de colonização como "a maneira através da qual os meios de comunicação influenciam o sistema político, a seleção e a forma das políticas e todo o processo político" (Meyer, 2002, p. xi). Em outras palavras, seu objetivo é estudar "as repercussões da mídia e da comunicação sobre a substância da política em si” (Meyer, 2002, p. xi).

De seu ponto de vista, o lugar central dos meios de comunicação na sociedade contemporânea vem levando outras áreas, especialmente a política, a se adaptarem às regras e códigos da mídia. Essa adaptação, segundo o autor, acontece em dois níveis: "a maneira como a mídia representa a política de acordo com suas regras específicas" e "o modo pelo qual a natureza da política é transformada como resultado de seu desejo constante de se submeter ao poder dessas regras" (Meyer, 2002, p. xii).

A política, explica, alterou sua própria lógica para se adaptar à lógica da mídia: "uma vez que a esfera da política cai sob a influência do sistema da mídia, ela muda consideravelmente: torna-se dependente das regras desta última, mas sem perder sua identidade própria (Meyer, 2002, p. 57).

Para ilustrar isso, o autor menciona como alguns políticos aprenderam a adaptar seus discursos e entrevistas para o timing da mídia, como partidos e governos criam ou expandem suas agências de comunicação e assessorias de imprensa enquanto a preocupação com a imagem pessoal se torna a primeira de muitos políticos. Essas práticas indicam que as regras e ações da mídia passam a ter alguma força normativa na política - a lógica da política foi adaptada para a lógica da mídia.

Por "lógica” Meyer compreende um grupo de regras e práticas que organizam as ações comuns de um grupo. A "lógica da mídia” diz respeito aos vários elementos do processo de comunicação, desde a maneira como jornalistas enquadram um evento ao escrever a notícia até as restrições de tempo em um programa de televisão - o "modo de ser" dos meios de comunicação. 
A política, explica Meyer, aprendeu a pensar na sua mensagem de acordo com a linguagem e os códigos da mídia, em particular os da televisão. Políticos não estão unicamente interessados nas discussões, na deliberação e na tomada de decisões, a matéria da política, mas também nas suas imagens e na sua figura pública, os elementos relacionados com a mídia. Meyer pensa no modo como os eventos políticos - a inauguração de uma obra pública, por exemplo - são planejados como "eventos de mídia” (Katz e Dayan, 1994), em uma hora e local que garantam ampla cobertura dos meios.

Meyer traça seu argumento sobre a noção de "colonização" da esfera pública na Modernidade seguindo o modelo das relações entre o "mundo da vida" e o "sistema" apresentado por Jürgen Habermas em sua Teoria da ação comunicativa (1987). Em sua análise do processo de modernização da sociedade ocidental, Habermas trabalha a partir do ponto de vista de uma progressiva racionalização de práticas e conceitos requeridos, argumenta, para o desenvolvimento do modelo capitalista. Nesse sentido, o "mundo da vida" foi "colonizado" pelas regras de mercado com vistas à proeminência e sobrevivência deste último. Conforme argumenta Meyer:

Jurgen Habermas introduziu e justificou a noção da colonização de um domínio social sobre outro em sua teoria da ação comunicativa. Ele procurava inventar uma linguagem conceitual capaz de descrever a conspícua e consequencial tendência na qual as regras do sistema político-administrativo e econômico dominavam progressivamente o mundo da vida na sociedade moderna. O mundo da vida tem uma origem e um papel específicos: é a parte da esfera social na qual a comunicação direta habilita as pessoas a deliberarem e atingir o consenso a respeito de assuntos que lhes concernem diretamente. (Meyer, 2002, p.56)

Ao retratar a política, a mídia não leva em conta sua natureza específica. Ao contrário, trata-a no mesmo nível de assuntos menos relevantes para o cidadão. E encontra, nisso, a cumplicidade do campo politico:

a colonização pela mídia força as organizações e instituições políticas, incluindo os parlamentos, a reagir melhorando e expandindo suas agências de comunicação, assessorias de imprensa e relações políticas, dotando-os de enormes recursos e equipando-os com um exército de consultores de mídia, tão hábeis no manejo das notícias quanto os próprios jornalistas. (Meyer, 2002, p. 58) 
No entanto, para Meyer, a "colonização" é um aspecto intrínseco da democracia moderna. Não haveria democracia, acredita, sem a presença dos meios de comunicação.

O debate, a deliberação e a busca de consenso entre os cidadãos são condições fundamentais da democracia. É necessário, argumenta Meyer (2002, p. 60), que as pessoas tomem conhecimento das decisões políticas - e o único canal para isso, na sociedade, é a mídia.

Nesse quadro, um pequeno grupo, o sistema político, é apoiado e legitimado por um grande número de pessoas. Isso conduz ao centro de seu argumento: as decisões do sistema político só podem atingir um grande número de pessoas se forem enquadradas pela mídia, como também aponta Kepplinger (2002) e Nazzari et alli (2007). Asim, o sistema político não tem opção senão adaptar-se aos "códigos e práticas" da mídia:

Legitimidade, elemento vital da política democrática, só pode ser conseguida através do apoio dado pelos cidadãos às decisões tomadas pelo sistema político, apoio definido pela percepção que se tem a respeito desse sistema - e a fonte primária dessa percepção é normalmente o que a mídia escolhe para retratar. (Meyer, 2002, p. 52)

Meyer também parece estar em débito com Habermas ao afirmar que o debate político atinge a esfera pública por meio da mídia. No entanto, Meyer argumenta que isso leva a uma espécie de gerenciamento da cena política na mídia:

Os fragmentos da realidade política escolhidos para ir ao ar são reunidos de acordo com regras que buscam em primeiro lugar criar uma apresentação que capture o máximo de atenção de um público específico. (Meyer, 2002, p. 30)

Outro exemplo tirado de Rees (1992) pode exemplificar esse fato - certamente exemplos brasileiros seriam inúmeros, mas o objetivo é mostrar que não se trata de um fenômeno exclusivo deste ou daquele país. Na eleição presidencial norte-americana de 1961, o debate entre os candidatos foi transmitido ao vivo na televisão pela primeira vez. John Kennedy e Richard Nixon eram os candidatos. Kennedy, bem-vestido, calmo, sabendo como se comportar diante da camera. Nixon, nervoso, transpirando, sem saber como lidar com o fato de estar na TV. Rees sugere que a aparência de Kennedy e sua facilidade com a linguagem televisiva foi decisive em sua vitória. 
O conceito de colonização de Meyer parece implicar a hegemonia de um campo sobre outro, sem maior perspectiva de uma resistência - a única defesa possível da política contra a mídia, ao que parece, é se juntar a ela.

\section{O entretenimento é uma forma de política}

As relações entre mídia, cultura pop e política são estudadas em outra perspectiva em três livros do pesquisador britânico John Street: Rebel rock (1986), Polítics and popular culture (1997) e Mass media, politics and democracy (2001).

A partir de estudos de casos, o autor sugere que, longe de ser simples diversão associada à alineação ou ao domínio político, o entretenimento pode ser pensado como um instrumento de ação política, inclusive para construção de resistências a um sistema hegemônico. Se, no tópico anterior, foi visto que a política se torna mais e mais uma apresentação de imagens para a mídia, por outro lado o entretenimento deixa de ser simples diversão.

Para Street $(1986 ; 1997 ; 2001)$, a força do entretenimento se deve a pelo menos dois fatores. De um lado, o alcance da mensagem. De outro, sua articulação com a vida das pessoas na criação de vínculos de identidade e comunidades. No mesmo sentido que Curran (2007), Street parece lidar com dois conceitos distintos e complementares de política - como prática partidária em um sistema democrático e, ao mesmo tempo, como a ação desse sistema nas normas da sociedade.

Street (2001, p. 21) mostra como a política partidária progressivamente se articulou com os meios de comunicação no sentido de aproximar sua mensagem do público - a participação de políticos em programas de auditório, apresentando-se como músicos durante as campanhas eleitorais ou tentando, de outras maneiras, criar vínculos entre a imagem séria e distante do político com a linguagem da televisão.

Em tempos de "showmícios", cantores eleitos e artistas de televisão eleitos para a Câmara dos Deputados e eleições conduzidas mais pelo marketing político do que por ideias e debates, é possível pensar como o entretenimento transforma o processo democrático:

A cultura pop se tornou, por conta de seus usos e a partir do valor dado a ela na sociedade, uma forma de atividade política. Ao mesmo tempo, a política contemporânea tem se conduzido no mesmo modelo e formato da cultura pop. (Street, 2007, p. 6) 
Street menciona, por exemplo, o ex-presidente norte-americano Bill Clinton tocando saxofone com um grupo de Jazz no dia de sua posse, ou as atitudes planejadamente teatrais dos candidatos durante as campanhas, criadas para ocupar espaço na mídia. É possível acrescentar, na realidade brasileira, a participação do senador Eduardo Suplicy em um capítulo da novela $O$ rei do gado, da Rede Globo, em 1997, ou a presença do então ex-presidente cassado Fernando Collor de Melo no Programa Raul Gil. O trânsito entre mídia e política pode mostrar sua vitalidade com ainda mais ênfase quando se pensa que entre os deputados federais mais votados nas eleições de 2006 estavam duas figuras da cultura pop, o cantor Frank Aguiar e o apresentador Clodovil Hernandes, e o recordista de votos em 2010 foi o palhaço Tiririca.

Por outro lado, Street não vê o entretenimento como um elemento passivo, mas como um canal para o questionamento de atitudes e situações. Focalizando particularmente o caso do rock'n'roll, Street (1986; 1997), acompanhando Frith (1984), indica como canções e músicos em muitas ocasiões atuam como uma espécie de porta-voz dos sentimentos de mudança.

A cultura pop pode, no sentido de apresentar várias formas de identidade, se misturar com a política, em particular no sentido relativo à cidadania, no direito a "fazer parte" e ser reconhecido. A cultura pop pode igualmente se tornar uma forma de resistência, como uma forma de desafiar ou mesmo negar o poder. (Street, 1997, p. 12)

Nesses termos, é impossível não lembrar do papel da música popular na recente política brasileira, sobretudo durante o período militar. Em certos casos, é o único canal disponível para alguma forma de contestação, e sua mensagem pode ser compreendida pelo público com todo o seu potencial político.

Street argumenta que isso acontece mesmo quando a mensagem não é explicitamente política; ao contrário, as atitudes e valores de um músico, por exemplo, podem ser interpretadas pelo público como mensagem política no sentido de colocar em questão ideias e valores. As roupas, o visual e o estilo podem igualmente ser vistos como um importante vetor no desenho das forças políticas de uma sociedade (Martino, 2010). Afinal, como define, a "cultura pop nem nos manipula nem é nosso espelho: ao contrário, nos vivemos com ela e ao seu redor. Não a imitamos mais do que ela nos imita, e, no entanto, nossas vidas estão vinculadas a ela" (Street, 1997, p. 4). 
As relações, no entanto, não se esgotam aí. Street (2001) mostra como os procedimentos rotineiros dos meios de comunicação - a prática da reportagem, por exemplo - interferem diretamente na representação do mundo político que chega até o cidadão: "O controle das informações é um atributo-chave para o controle do poder, e a mídia pode ser um instrumento para isso" (Street, 2001, p. 91).

O discurso da mídia é preparado para conferir a si mesmo uma aparência de realidade e credibilidade. Os processos de produção da notícia, bem como a autorrepresentação dos jornalistas, criam a impressão de separação entre a mídia e o corpo politico. Essa ilusão de independência pode ser um elemento na criação de condições favoráveis para que as transformações da política na mídia passem despercebidas.

Ao apropriar e ser apropriada pela esfera do entretenimento, a política se esconde sob proteção de seu antípoda: afastado de tudo o que é sério, o entretenimento seria o último lugar onde se poderia imaginar uma mensagem política - e, no entanto, é onde conteúdos políticos podem estar.

Políticos têm cada vez mais atuado como atores, músicos e estrelas do esporte. Fazem isso não apenas em premiações ou situações especiais, mas também dividindo palcos e espaços que celebridades conquistaram. (Street, 2001, p. 190)

Essa interseção, no entanto, aproxima a política perigosamente do domínio das coisas que não são sérias - levando em conta que o entretenimento, em princípio, não teria efeitos no campo politico. Uma hipótese de convergência ainda mais explícita entre os campos é apresentada por Liesbet Van Zoonen, no próximo item.

\section{A hipótese da convergência: a política tomou a forma da mídia}

É ilusão acreditar que a política pode atrair a atenção das pessoas por suas características próprias. A tomada de decisões, a deliberação, e as ações do Executivo e do Legislativo interessam apenas aos seus participantes diretos. Para chegar até o público, a política precisa ser mostrada em uma linguagem compreendida por todos. E o melhor modelo é o entretenimento - que, por sua vez, oferece formas até então desconhecidas de mobilização social e tomada de decisões. Essa é a tese de Liesbet Van Zoonen em seu livro Entertaining the citizen (2005). 
A dissolução das fronteiras delimitando entretenimento e política são sintomas, acredita, de um processo mais amplo de disseminação dos formatos da mídia pela sociedade. Enquanto locus de ação política, a mídia torna-se o epicentro do engajamento cívico contemporâneo em situações inéditas que exigem repensar alguns conceitos centrais - as noções de "engajamento" e "participação", em primeiro lugar, e mesmo a concepção de política, como lembram McNair, Hibberd e Schlesinger (2002, p. 408).

Van Zoonen sugere uma equivalência entre "ação política" e a participação dos cidadãos em algum tipo de causa - ainda que essa "causa" seja a votação de um reality show. A mediatização da sociedade leva a novas formas de participação, deliberação e engajamento dos cidadãos. Na mídia, a política disputa espaço com o entretenimento e, de algum modo, precisa se remodelar em termos desse formato para concorrer pela atenção do público.

Van Zoonen não parece ver nisso uma transformação da política como um todo; algumas características específicas se mantêm intactas, mas a forma de relação com o público é alterada. O processo de midiatização da política, diz ela, acontece em dois sentidos. De um lado, trata-se da apresentação da política como fenômeno midiático de entretenimento, adotando suas práticas, formatos e gêneros. De outro, propõe que o engajamento cívico encontra sua realização na esfera do entretenimento - um dos aspectos ousados de seu livro:

Prazer, fantasia, diversão, amor, dedicação e despersonificação não são conceitos que se reconciliam facilmente com virtudes cívicas como o a racionalização, desinteresse, conhecimento e liderança. (Van Zoonen, 2004, p. 63)

No primeiro caso, pode-se pensar como a vida pessoal dos políticos ganha feições de ficção televisiva - Muir (2005) menciona que uma senadora australiana de um partido pequeno recebia grande atenção da mídia por conta da bela aparência - assim como escândalos e dilemas políticos são tratados pela mídia como uma espécie de teledramaturgia com heróis, vilões e lances espetaculares em lugar do foco em debates ou propostas. A política partidária, na mídia, torna-se a política da personalidade (Gomes, 2003; Gomes e Maia, 2008).

A apresentação de fatos é feita como lances dramáticos de um roteiro, ao mesmo tempo em que a apresentação dos eventos cruciais recordam a dramaturgia: 
políticos precisam alternar constantemente entre as demandas da política e do entretenimento para manter sua posição e status no campo político bem como sua presença na cultura cotidiana de seus eleitores. (Van Zoonen, 2005, p. 69)

Nas entrelinhas, parece sugerir que a democracia ganha novos significados na mídia.

A noção de política, nesse caso, parece bastante elástica, podendo incluir em si a participação em um programa de TV e a preocupação com questões efetivamente vinculadas à vida cotidiana dos indivíduos. Não seria isso, de alguma maneira, pretender uma equivalência entre esferas completamente diferentes? Afinal, a política trata de assuntos sérios, enquanto o entretenimento está ligado ao gasto de um tempo supérfluo?

Em princípio, sim, explica Van Zoonen, mas se pensarmos em uma concepção de "política" que leva em conta apenas os participantes do campo político. Como forma de despertar e obter o engajamento dos cidadãos, argumenta, o entretenimento apresenta-se atualmente muito mais efetivo do que a discussão política tradicional.

A midiatização da política converge com uma politização do entretenimento devido à força de mobilização deste último. Quando a final de uma edição do Big brother consegue obter dezenas de milhões de votos, o fato de um número expressivo de indivíduos tomar a iniciativa de dar parte de seu tempo, dinheiro e inteligência para votar pode, acredita a autora, ser considerado uma forma de engajamento. Em particular, se o interesse dos cidadãos é deliberar sobre o vencedor do reality show, quesitona, isso seria um engajamento "político"?

Van Zoonen procura ultrapassar uma dicotomia entre "política" e "entretenimento", divisão entre o assunto "sério" e o "frívolo" propondo uma convergência entre ambos, embora em um diálogo cheio de contradições. A confluência não representa necessariamente uma perda para a política, mas sua adaptação aos novos interesses da população - se o comportamento político, no sentido de interferência na vida da polis, é a deliberação do reality show, a política talvez se aproxime do entretenimento como linguagem para levar ideias e usando sua força de mobilização para outras esferas:

Na carga crescente de textos e imagens do entretenimento, a performance individual dos políticos é um caminho mais curto para oferecer aos cidadãos a informação necessária para fazer seus julgamentos políticos. (Van Zoonen, 2005, p. 69) 
Um espaço particular é dedicado por Van Zoonen ao comportamento dos fãs. Um fã, explica, não é apenas alguém que admira ou gosta de algum produto da mídia. Dentre as pessoas que se denominam “fãs", é possível traçar um continuum entre dois extremos, da pessoa que aprecia moderadamente até o "fan" - abreviação, em inglês, para "fanático".

A diferença específica do fã é seu engajamento com o objeto em questão. $\mathrm{O}$ fã mantém uma relação ativa com a produção midiática. Trata-se de uma forma mais complexa e duradoura de apropriação - ele interage com outros fãs para debater, participa de fóruns de discussões a respeito, em que discute com uma comunidade igualmente interessada em compartilhar conhecimentos específicos. Van Zoonen destaca três aspectos dessa relação: o engajamento com o tema no sentido de conhecê-lo a fundo; o vínculo comunitário, no qual há troca de informações e opiniões; a dedicação, traduzida em tempo, afeto e inteligência na relação com o objeto de admiração.

Ela sublinha a proximidade dessas práticas com o engajamento cívico na democracia. Van Zoonen (2005, p. 74) parece sugerir uma migração de interesses de um campo para outro, e vê na "democracia dos fãs" evidência de que o entretenimento tem um potencial de atração para a discussão social dos assuntos de interesse comum; no entanto, critica um deslocamento no foco na medida em que essa deliberação não está vinculada ao modelo tradicional de política, mas à política midiática.

O que propõe Van Zoonen não é a existência de qualquer equivalência, mas uma questão relativa à natureza dessa ação: a organização de pessoas na deliberação a respeito de um assunto que, em última análise, se converte na ação do voto e, portanto, em uma tomada de decisão, não seria um componente da democracia? Em tempos de política mediada, talvez - seja na eleição ou na eliminação de um candidato.

\section{Considerações finais}

As relações entre mídia e política estão, cronologicamente, entre as primeiras preocupações dos estudiosos da comunicação (Martino, 2009). $\mathrm{O}$ que parece ser a diferença específica das hipóteses formuladas neste início de século XXI, e sinteticamente expostas neste texto, é a presença do entretenimento como fator de alteração nas relações entre mídia e política. Pode-se objetar, com razão, que o entretenimento sempre esteve diretamente ligado com a política. 
No entanto, essa ligação tendia a ser vista de maneira potencialmente negativa. $\mathrm{O}$ que estas hipóteses contemporâneas parecem indicar é um redimensionamento crítico do entretenimento, visto não como um elemento potencialmente negativo, mas como um espaço de conflito e negociação de sentidos entre um público e os textos culturais dos quais se apropria. Nesse sentido, as três hipóteses - colonização, convergência, ação política - parecem convergir em uma perspectiva crítica, mas não destrutiva, ao entretenimento, pensado como um local dinâmico de conflito. E talvez de diálogo.

\section{Referências bibliográficas}

BRANTS, Kees \& NEIJENS, Peter. 1998. “The infotainment of politics”. Political Communication, n. 15, p. 149-164.

CURRAN, James. 2007. "Reinterpreting the democractic roles of the media". Brazilian Journalism Research, v. 3, n. 1, p. 31-54.

FRITH, Simon. 1984. "Rock and politics of memory". Social Text, n. 9/10, p. 59-69.

GOMES, Wilson. 2003. Transformações da política na era da comunicação de massa. São Paulo: Paulus.

\& MAIA, Rousiley. 2008. Comunicação e política. São Paulo: Paulus.

HABERMAS, Jürgen. 1985. Theory of communicative action. Boston: Beacon Press.

KATZ, Elihu. 1957. "The two-step flow of communication". The Public Opinion Quarterly, v. 21, n. 1, p. 61-78.

\& DAYAN, Daniel. 1994. Media events. Harvard: Harvard University Press.

KEPPLINGER, Hans Mathias. 2002. "Mediatization of politics: theory and data”. Journal of Communication, v. 52, n. 4, p. 972-986.

LASSWELL, Harold. 1957. "The structure and function of communication in society”. In: SCHRAMM, Wilbur \& ROBERTS, Donald (eds.). The process and effects of mass communication. Chicago: University of Illinois Press.

LOUW, Eric. 2005. The media and political process. London: Sage.

McCOMBS, Maxwell \& SHAW, Donald. 1972. "The agenda-setting function of mass media”. Public Opinion Quarterly, v. 36, n. 2, p. 176-187.

MARTINO, Luís Mauro Sá. 2009. Teoria da comunicação. Petrópolis, RJ: Vozes. 
2010. Comunicação e identidade. São Paulo: Paulus.

McNAIR, Brian; HIBBERD, Max \& SCHLESINGER, Philip. 2002. "Public access broadcasting and democratic participation in the age of mediated politics". Journalism Studies, v. 3, n. 3, p. 407-422

MEYER, Thomas. 2002. Media democracy. London: Polity.

MUIR, Kathie. 2005. "Media darlings and falling stars: celebrity and the reporting of political leaders". Westminster Papers in Communication and Culture, v. 2, n. 2, p. 54-71.

NAZZARI, Rosana et alli. 2007. "Democracia virtual e capital social: internet e comportamento político". Ciências Sociais em Perspectiva v. 6, n. 11, p. 77-92

PANKE, Luciana. 2010. "Política e entretenimento: cruzamento e/ou interferência na construção de sentidos”. Animus, v. 18, n.1, p. 13-30.

POSTMAN, Neil. 1986. Amusing ourselves to death. London: Penguin.

PUTNAM, Robert. 1995. Bowling alone. New York: Simon \& Schuster.

REES, Lawrence. 1992. Selling politics. London: BBC Books.

STREET, John. 1986. Rebel rock. London: Blackwell.

1997. Politics and popular culture. London: Temple.

2001. Mass media, politics and democracy. London: Polity.

. 2005. "Politics lost, politics transformed, politics colonised? theo-

ries of the impact of mass media". Political Studies Review, v. 3, p. 17-33.

VAN ZOONEN, Liesbet. 2004. "Imagining fan democracy”. European Journal of Communication, v. 19, n. 1, p. 39-52.

2005. Entertaining the citizen. London: Bowman \& Littlefield.

\section{Resumo}

Este texto apresenta e discute três hipóteses contemporâneas sobre as relações entre mídia e política. A expressiva votação obtida por celebridades e figuras do entretenimento nas eleições recentes vem levando pesquisadores de várias áreas a analisar a questão. Neste texto são discutidas três propostas: (a) a hipótese de Thomas Meyer sobre como a mídia "colonizou" a política; (b) a argumentação de John Street sobre o entretenimento como forma de política e (c) a hipótese de Van Zoonen, para quem o entretenimento e política convergem na forma e na força de produzir engajamento cívico. Finalmente, um breve comentário aponta semelhanças e diferenças entre as teorias.

Palavras-chave: mídia; entretenimento; política; democracia. 


\begin{abstract}
This paper outlines and discusses three hypotheses on the relationship between politics and entertainment. It seems that as politicians have become media stars and artists have entered the political arena, it is necessary to clarify the reasons why this is happening. In this paper three ideas are summarized: (a)Thomas Meyer's argument that'media has colonized democracy'; (b) John Street's view about the popular culture's political importance and (c) Liesbet Van Zoonen's notion of 'convergence' between entertainment and politics. Finally, a brief critical account of these hypotheses is done to frame them into a larger picture.
\end{abstract}

Key words: media; entertainment; politics; democracy.

Recebido em março de 2011.

Aprovado em junho de 2011. 